The Industrial/Consumer Dichotomy in Marketing: Can Formal Taxonomic Thinking Help? ${ }^{1}$

\title{
Ross Brennan
}

\section{Until 30 ${ }^{\text {th }}$ April 2012}

Middlesex University Business School

The Burroughs

Hendon, NW4 4BT

United Kingdom

Tel. +442084115861

Fax. +442084114212

Email: r.brennan@mdx.ac.uk

From $1^{\text {st }}$ May 2012

University of Hertfordshire

Business School

Hatfield

Hertfordshire

AL10 9AB

Contact details to be confirmed

Ross Brennan was awarded his PhD in business-to-business marketing by UMIST in 1998. He worked as a manager in the telecommunications industry before joining Middlesex University Business School. Currently, he is Reader in Marketing at the University of Hertfordshire Business School. Ross specialises in business-to-business marketing, having co-authored a B2B textbook with Louise Canning and Ray McDowell, and published many journal articles and conference papers in the field. Dr. Brennan is on the editorial advisory boards of Industrial Marketing Management, the Journal of Business-to-Business Marketing, and Marketing Intelligence \& Planning.

\footnotetext{
${ }^{1}$ This is a preprint (pre peer-review) version of a paper submitted for consideration for the Journal of Customer Behaviour, (C) Westburn Publishers Ltd, http://www.westburn.co.uk
} 


\title{
THE INDUSTRIAL/CONSUMER MARKETING DICHOTOMY IN MARKETING: CAN FORMAL TAXONOMIC THINKING HELP?
}

\begin{abstract}
The question of whether or not there exists a dichotomy between industrial (business-tobusiness) and consumer marketing has never been satisfactorily answered. Prominent authors champion both sides of the debate. This paper places the debate in the broader context of formal taxonomic thinking, and so seeks to resolve the issue at a more fundamental level than the practice of marketing. The argument presented here is that the validity of the industrial/consumer dichotomy should be addressed through an understanding of scientific taxonomy. The science of taxonomy is highly developed in other fields of study. It is argued in this paper that the industrial/consumer dichotomy fails to meet the criteria for a logically based, general taxonomic framework. Rather, the dichotomy has the weaker characteristics of a special or 'folk' taxonomic framework. Scientific effort in marketing should be directed towards the development of valid marketing classifications based on sound taxonomic principles.
\end{abstract}

\section{KEYWORDS}

Business-to-business; taxonomy; marketing; systematics 


\section{INTRODUCTION AND BACKGROUND}

Nearly thirty years after Fern and Brown (1984) argued that there was insufficient justification for the dichotomy between industrial and consumer marketing, the debate on the fundamental right of industrial marketing (cf. business, business-to-business or organisational marketing) to exist as a separate field of study remains open. Fern and Brown challenged the industrial/consumer marketing dichotomy on three grounds:

- The classification does not adequately partition marketing phenomena.

- Counter-examples which point to the lack of differences are readily available.

- The differences within industrial and consumer marketing are greater than the differences between them.

An examination of the literature since 1984 suggests that, while many authors have reiterated the industrial/consumer dichotomy in one form or another, few people have really engaged with (still less refuted) these arguments.

To contend that the debate about the distinction between industrial/business marketing and consumer marketing rages on might rather over-state the case, but it certainly smoulders on. Influential authorities seem to stand on both sides. While Lichtenthal et al (2006) contend that 'we are all business marketers now' and that business marketing ideas should have greater influence throughout the marketing field, Wind (2006) argues that a 'blurring of the lines' has rendered business and consumer marketing increasingly similar. Lichtenthal and Mummalaneni 
(2009, p. 41) talk of 'fundamental differences in both conceptual and tactical issues, suggesting a unique foundation', while, on the other hand, Cova and Salle (2008) suggest that servicedominant logic provides an umbrella under which industrial/business and consumer marketing can be united.

One possible answer to this dilemma was presented by the development of relational approaches to marketing in the 1980s and 1990s. Perhaps industrial/business marketing is largely about 'relationships', while consumer marketing is largely about 'transactions'? A key feature of the decades since the publication of Fern and Brown's famous paper has been the development of more relational approaches to marketing. Mattsson (1997) argued that this has spawned two parallel streams of literature-relationship marketing, and the interaction and networks (or IMP) approach — with the former focusing rather more on consumer marketing and the latter exclusively on industrial marketing. A key aim of scholars in the interaction and networks tradition has been to differentiate industrial marketing from consumer marketing, on the grounds that industrial buying and selling are elements in an interaction process in which both parties are active participants. It has become something of a theme in IMP literature that relationship marketing is primarily consumer-orientated, and implies an active seller with a relatively passive buyer, whereas the interaction and networks approach stresses the active participation of both actors (Ford et al 2002, 2011). However, Coviello and Brodie (2001, pp 394-395), in an empirical study based on a relational marketing conceptual framework, found that: '... while certain differences do emerge between consumer and B2B firms ... the general patterns of behavior are more similar than not', and concluded that: ' $\ldots$ it is unreasonable to argue that marketing practices are fundamentally different across consumer and B2B firms.' Pels (1999, pp 
30-31) reinforced the view that it is invalid to pigeonhole the IMP approach as only applicable to business markets. She argued that 'the network approach must be applied' whenever actors are willing to engage in relational exchange, and that: '.. from a theoretical point of view, the interaction and network approach can be applied to both business and consumer markets.'

Consequently, it seems that we are still left with an unanswered question, namely whether industrial and consumer marketing are fundamentally different practices, or are simply slightly differentiated contexts for the application of general marketing principles. The neat solution that the relational marketing revolution might have brought about—business-to-business is relational, business-to-consumer is transactional-seems not to hold water. While this is an issue, presumably, of only limited interest to the marketing practitioner-who is more concerned about getting on with the job than knowing whether what s/he does can be neatly compartmentalisedit should be of greater concern to researchers and educators in the field. To the educator, it should matter whether the rather glib distinction between industrial and consumer marketing that introduces the first lecture on a business-to-business course (and is assigned reading from chapter one of the textbook) is valid or not. The researcher really ought to be concerned, when framing his or her research problem, whether or not it is legitimate to assume a fundamental difference between consumer and business markets, or buying behaviour, or marketing practice.

This paper re-examines the industrial/consumer marketing dichotomy using the lens of formal taxonomy. First, it compares and summarises prior work delineating industrial and consumer marketing, and applies some elementary taxonomic logic to the issue. Second, rather more fundamental questions about the meaning of the industrial/consumer dichotomy are asked by 
drawing upon the literature of systematics and taxonomy in other fields of study. The paper then concludes with an assessment of the robustness of the industrial/consumer dichotomy, and recommendations for further research.

\section{FACTORS DISTINGUISHING INDUSTRIAL AND CONSUMER MARKETING}

A brief digression on terminology may help at this point. Today's preferred expression for the marketing of goods and services between organisations is 'business marketing'. Since this paper takes as its inspiration the work of Fern and Brown (1984), the older term 'industrial marketing' will often be preferred in this paper; Fern and Brown made it clear that they used the term to refer to the marketing of both goods and services.

It is, of course, quite easy to find lists of factors differentiating consumer marketing from industrial marketing. However, in discussing the industrial/consumer dichotomy authors have not always made it clear whether they are talking about differences at the level of market structure, of buying behaviour, or of marketing practice. Table 1 contains a small selection of the attempts to list the distinguishing features of consumer and industrial markets.

[Insert Table 1 about here] 
Table 1: Factors characterising industrial marketing

\begin{tabular}{|c|c|c|c|}
\hline Lilien (1987) & Webster (1991) & Wilson (1999) & Ford et al (2002) \\
\hline 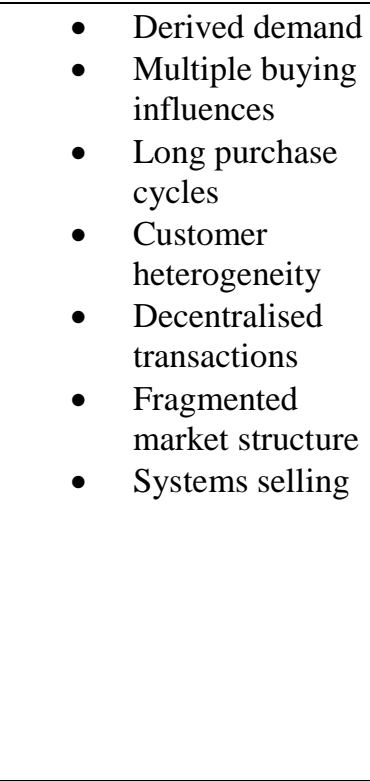 & $\begin{array}{ll}\text { - } & \text { High } \\
\text { transaction } \\
\text { value } \\
\text { - } & \text { Multiple } \\
\text { buying } \\
\text { influences } \\
\text { Derived } \\
\text { demand } \\
\text { - } & \text { Functional } \\
\text { inter- } \\
\text { dependence } \\
\text { - } \\
\text { Product } \\
\text { complexity } \\
\text { Buyer-seller } \\
\text { inter- } \\
\text { dependence } \\
\text { Buying } \\
\text { process } \\
\text { complexity }\end{array}$ & $\begin{array}{ll}\text { - } & \text { Market } \\
& \text { complexity } \\
\text { - } & \text { Large } \\
\text { market size } \\
\text { - } & \text { Derived } \\
\text { demand } \\
\text { - } & \text { Small } \\
\text { number of } \\
\text { buyers } \\
\text { - Large order } \\
\text { size }\end{array}$ & $\begin{array}{ll}\text { - } & \text { Purchase process } \\
& \text { complexity } \\
\text { - } & \text { Purchase process } \\
& \text { professionalism } \\
\text { - } & \text { Long purchase } \\
\text { cycles } \\
\text { - } & \text { Buyer-seller } \\
& \text { inter-dependence } \\
\text { - } & \text { Relationships } \\
\text { - } & \text { An interactive } \\
& \text { process }\end{array}$ \\
\hline
\end{tabular}


What is immediately clear is that while there is no single, agreed list of the characteristics of industrial markets there certainly are recurring themes (for example derived demand and purchase process complexity). Slightly longer reflection confirms that aspects of market structure, buying behaviour characteristics, and marketing practice are intermingled in these lists. For example, Lilien (1987) mentions derived demand (market structure), long purchase cycles (an aspect of buying behaviour), and systems selling (an aspect of marketing practice). One aspect of a taxonomic system upon which many authors agree is the desirability of establishing a taxonomic hierarchy (Chrisman, Hofer \& Boulton 1988, McKelvey 1982, McCarthy 1995). A likely candidate for a three-level hierarchy of differences between industrial and consumer markets is the distinction between market structure, buying behaviour, and marketing practices. This is based on the proposition that differences in marketing practices between industrial and consumer markets can be traced to differences in buying behaviour and market structure. For example, face-to-face selling is often preferred in industrial markets because the purchasing process is complex (so that explanations of how the seller's technology will contribute to the solution of the buyer's business problem need to be adapted to individual circumstances), and because, often, there are few buyers and they buy in large quantities (justifying the costs involved in maintaining a field sales force). For basic consumer goods neither of these conditions holds (there are many customers and they are presumed to know what they want from the product), so that mass communication methods can be employed effectively.

Table 2 presents a more comprehensive analysis of the claimed differences between industrial and consumer marketing, and further classifies those differences into the categories market 
structure, buying behaviour, and marketing practice. The essence of this argument is that market structure differences are more or less exogenous to the firm (although it is true that some firms can alter the market structure through mergers and acquisitions), that buyer behaviour is substantially influenced by market structure, and that marketing practice is substantially affected by both market structure and buyer behaviour.

In the language of taxonomy the authors represented in table 2 are identifying 'characters' and 'character states' for 'specimens'. Quicke (1993, p11) observed that: 'The raw data of both numerical taxonomy and phylogenetic methods are generally taxa versus character matrices ...' Table 2 is a rudimentary taxa versus character matrix. It shows the proposed characters and character sets for two taxa - namely industrial marketing and consumer marketing. For example, in this framework the nature of demand is a taxonomic character, with two character states (derived or direct). Demand elasticity is a taxonomic character that is metric in nature; several authors have contended that demand tends to be less elastic with respect to price in industrial markets than it is in consumer markets, and that inverse (or reverse) price elasticity is found more often in business than consumer markets.

[Insert Table 2 about here] 
Table 2: B2B and B2C marketing - market structure, buying behaviour, marketing practice

\begin{tabular}{|c|c|c|}
\hline \multicolumn{3}{|c|}{ MARKET STRUCTURE DIFFERENCES } \\
\hline Taxonomic character & Business marketing & Consumer marketing \\
\hline Nature of demand & Derived & Direct \\
\hline Demand volatility & Greater volatility & Less volatility \\
\hline Demand elasticity & Less elastic & More elastic \\
\hline Reverse elasticity & More common & Less common \\
\hline Nature of customers & Greater heterogeneity & Greater homogeneity \\
\hline Market fragmentation & Greater fragmentation & Less fragmentation \\
\hline Market complexity & More complex & Less complex \\
\hline Market size & Larger overall value & Smaller overall value \\
\hline Number of buyers per seller & Few & Many \\
\hline Number of buyers per segment & Few & Many \\
\hline Relative size of buyer/seller & Often similar & Seller much larger \\
\hline Geographic concentration & Often clustered & Usually dispersed \\
\hline \multicolumn{3}{|c|}{ BUYING BEHAVIOUR DIFFERENCES } \\
\hline Taxonomic character & Business marketing & Consumer marketing \\
\hline Buying influences & Many & Few \\
\hline Purchase cycles & Often long & Usually short \\
\hline Transaction value & Often high & Usually small \\
\hline Buying process complexity & Often complex & Usually simple \\
\hline Buyer/seller interdependence & Often high & Usually low \\
\hline Purchase professionalism & Often high & Usually low \\
\hline Importance of relationships & Often important & Usually unimportant \\
\hline Degree of interactivity & Often high & Usually low \\
\hline Formal, written rules & Common & Uncommon \\
\hline \multicolumn{3}{|c|}{ MARKETING PRACTICE DIFFERENCES } \\
\hline Taxonomic character & Business marketing & Consumer marketing \\
\hline Selling process & Systems selling & Product selling \\
\hline Personal selling & Used extensively & Limited \\
\hline Use of relationships & Used extensively & Limited \\
\hline Promotional strategies & Limited, customer-specific & Mass market \\
\hline Web integration & Greater & Limited \\
\hline Branding & Limited & Extensive, sophisticated \\
\hline Market research & Limited & Extensive \\
\hline Segmentation & Unsophisticated & Sophisticated \\
\hline Competitor awareness & Lower & Higher \\
\hline Product complexity & Greater & Lesser \\
\hline
\end{tabular}

Sources: Lilien (1987), Webster (1991), Wilson (1999), Dwyer \& Tanner (2002), Chisnall

(1989), Ford et al (2002), Simkin (2000), Wilson \& Woodside (2001) 


\section{THE INDUSTRIAL/CONSUMER DICHOTOMY AS A TAXONOMIC FRAMEWORK}

\section{Problems with the amateur approach to taxonomy}

All of the extant justifications of the industrial/consumer dichotomy start from the premise that the taxonomy 'exists', and then claim to demonstrate why 'reality' is the way it is. Working from common sense observation of reality to taxonomic conclusions in this way is flawed. To understand the difficulty with this approach, one need only apply a biological analogy: by starting from the common sense observation that bipeds and quadrupeds represent a fundamental dichotomy in the animal world, one would end up with an erroneous scheme, judged by scientific criteria. At the same time, it is important to realise that such common sense taxonomies may have practical value. For example, the classification of animals into the categories 'dangerous' and 'harmless', although without a scientific basis, was no doubt of great value to hunter/gatherer tribes. The industrial/consumer dichotomy may be such a classification scheme; one that is based in common sense, has (or used to have) some practical value, but does not meet the criteria for a scientific taxonomy.

Otherwise careful authors seem to exhibit a blind spot when it comes to the industrial/consumer dichotomy. Chisnall made the following logically erroneous comparison between industrial capital purchases and consumer convenience purchases (why not compare industrial capital purchases with consumer durable purchases?). 
'capital equipment ... Such products tend to be bought fairly infrequently by any one organisation, furthermore, they are distinctly different from high-frequency purchases of consumer products such as food in that purchase can often be postponed for long periods of time' (Chisnall 1989, p38)

The following two further examples suggest that, when attempting to make the distinction between business/industrial markets and consumer markets, authors do not always demonstrate exemplary rigour.

'One distinction between business markets and consumer markets is that customers in business markets predominantly focus on functionality or performance, whereas customers in consumer markets predominantly focus on aesthetics or taste' (Anderson \& Narus 1999, p5)

Presumably the one billion people in the world living on a daily income of less than US\$1 do not focus predominantly on aesthetics or taste (Barber, 2008). More generally, if this assertion is true at all, then presumably it is only true for a small and privileged minority of consumers, and perhaps only for a sub-set of products (for example, true for clothing purchases, but untrue for household cleaning products).

'Business markets have fewer sellers and decidedly fewer buyers in any market segment than do consumer markets. Competition in business markets tends to be more oligopolistic (fewer sellers and many buyers), whereas consumer markets are more monopolistic (many buyers and sellers, and differentiation among competing products)' (Gross et al 1993, p17). 
While one assumes that Gross et al (1993) are trying to claim that consumer markets exhibit monopolistic competition (Chamberlin 1946) in contrast to oligopoly, what they actually say is that consumer markets are monopolistic. Whatever the assertion, the evidential basis is not at all clear. One does rather get the feeling that the dichotomy between consumer and industrial marketing is deemed to be so obvious that a carefully argued justification is not really necessary.

\section{Systematics, taxonomy, and science}

In the foregoing sections it has been asserted that the attempts to defend the industrial/consumer dichotomy are logically flawed and often weakly argued. The question arises: what should be put in place of this flawed classification? An answer is sought in the fields of systematics and taxonomy (note that a brief glossary is provided at the end of the paper). Systematics is the science of the diversity of form, while taxonomy concerns the theory and practice of classifying things. Two key assertions emerge from a study of the literature on systematics and taxonomy. First, that classifying things is something that seems to be an intrinsic part of human nature.

'The need to produce a scheme which will pigeon-hole an individual entity is natural to the human brain.' (McCarthy 1995, p37)

'It appears that the human being is by nature a classifying animal as his functioning and survival seem to have depended on his ability to recognize and communicate similarities and differences between objects and events in his universe ... Ontologically, it has been proposed that the 
development of reason in the child is fundamentally involved with "grouping" operations and dichotomous distinctions.' (Mezzich and Solomon 1980, p1).

The second key assertion is that systematics, and the development of valid taxonomies, are fundamental to sound scientific enquiry.

'Perhaps the most important and basic step in conducting any form of scientific inquiry involves the ordering, classification, or other grouping of the objects or phenomena under investigation.' (Carper \& Snizek 1980, p65)

'Systematics is not an outgrowth of sound scientific method in most sciences; it is a prerequisite to such methods.' (McKelvey 1982, p3, emphasis in original)

Much of what we know about the fields of systematics and taxonomy has emerged from the biological sciences, particularly botany and zoology (Blackwelder 1967). The modern study of systematics is usually traced back to the work of Carolus Linnaeus in the seventeenth century (McKelvey 1982). It is only in relatively recent times that scientists have sought formally to apply the methods of systematics to behavioural sciences (Mezzich \& Solomon 1980). There is some evidence of increasing interest in the formal application of systematics and taxonomy to the managerial sciences. For example, Carper and Snizek (1980) and McKelvey (1982) addressed the classification of organisational types, Chrisman, Hofer and Boulton (1988) considered the classification of business strategies, while McCarthy and colleagues have applied 
formal systematic method to the classification of manufacturing systems (McCarthy 1985, McCarthy \& Ridgway 2000).

McKelvey (1982) and McCarthy (1995) agree that four underlying theories of classification can be identified. They are essentialism (typology), nominalism, empiricism (numerical taxonomy), and phyletics - within which there are two important variants, cladism and evolutionism. In essentialism the aim is to classify together entities that share a common essence or hidden reality; manifest characteristics (taxonomic characters) are used to do this. By contrast, the nominalist approach contends that groups do not really exist, but are merely human constructs only individual entities exist. Hence nominalist classification holds no intrinsic meaning, but is a purely instrumental activity aimed at assisting practical scientists. Empiricism (numerical taxonomy, phenetics) constitutes the identification of groups based on statistical analysis of taxonomic characters (attributes); entities which are similar in terms of taxonomic characters are placed in the same group. Phyletics (evolutionism, cladism) is based on the evolutionary idea that 'the natural groupings of biological organisms were due to their descent with modification from common ancestors' (McKelvey 1982, p49, emphasis in original). Hence phyletics is the only theory that attempts to explain the origin of groupings as well as classify them - it combines explanation with classification. Evolutionism and cladism, both forms of phyletics, diverge over the best method of identifying evolutionary affinity between entities. Cladism emphasises the recency of descent from a common ancestor, while evolutionism emphasises the number of similar genes that members of a group have in common. 
Both McCarthy (1995) and McKelvey (1982) argued that essentialism and nominalism are obsolete, whether for the classification of biological or organisational phenomena. The focus of attention, therefore, has been on the application of numerical taxonomy and phyletic methods in management fields. McKelvey's particular interest lies in the classification of organisations, and for this he advocates a combination of the phyletic and empiricist methods. He argues, first, that organisational evolution does take place across generations, and, second, that the complexity of organisational forms lends itself well to the multivariate statistical analysis characteristic of the phenetic approach. While McKelvey explicitly rejected cladism for organisational analysis, principally on the grounds that 'it will produce too complex a classification' (p60), others (McCarthy 1995, McCarthy \& Ridgeway 2000) have argued forcibly for the use of cladistics as the basis for classifying manufacturing systems and organisations.

\section{'Special' classifications and 'folk' classifications}

McKelvey (1982) stressed the importance of the distinction between 'special' and 'general' classifications: 'Special classifications group objects together on the basis of a small, selected number of attributes of particular interest ... A general classification attempts to group objects together on the basis of all their attributes' (McKelvey 1982, pp 15-16). A special classification focuses on one, or a few, attributes - for example, edible and non-edible plants. Such a classification has high predictive validity within a narrow range of attributes, but 'special classifications do not allow for very good information-retrieval systems' (McKelvey 1982, p16). In other words, members of a taxon within a special classification are similar to each other in one (or a few) key ways, but there is no reason to believe that they will be similar in any other 
characteristics. Hence, findings from one study of members of a special classification cannot be reasonably generalised to all members of that taxon. For example, to find that one variety of edible plants thrives in acidic soil says nothing about other varieties of edible plants.

On the other hand, a general classification is based on a wide range of attributes. Members of a taxon of a general classification are broadly alike along many dimensions. This means that such a classification system is not as sharply predictive as a special classification with respect to any single attribute. Rather, a general classification is broadly predictive of the total behaviour of members of a class. This provides a useful information-retrieval system for scientific knowledge. Studies of members of a taxon within a general system of classification can reasonably be generalised to other members of that taxon. Therefore, a general classification system is a useful way of organising a scientific discipline since it provides a solid foundation for replicating prior studies and for generalising from research findings. In the absence of a general classification system, it is difficult to see how replication studies can be conducted using a logically relevant sample, or how generalisation can be applied to a logically relevant population.

One interpretation of the industrial/consumer dichotomy is that it is a special classification, rather than a general classification. It has high predictive validity in one respect, namely, the nature of the customer. However, if it is a special classification it has very limited wider predictive power. In that case there would be no reason to suppose that the industrial/consumer dichotomy is a logical basis for the generalisation of research findings 
Mezzich and Solomon (1980) remark upon the existence of 'folk taxonomies' developed by human communities as a means of categorising and communicating about the world around them. These are akin to special classifications, in that they are based on one or a few attributes, facilitate communication about the entities involved, but are not designed for information retrieval. The notion of a folk taxonomy is similar to the idea of a taxonomy based on common sense observation of reality, discussed above. It is worth reiterating that such taxonomies, although with no foundation in scientific theory may, nevertheless, have genuine practical utility. It seems likely that the industrial/consumer dichotomy is, in fact, a folk taxonomy developed by marketing practitioners to serve their own purposes. This would explain why a taxonomy with such limited wider empirical support remains so pervasive.

\section{Conclusion and further research}

Sheth, Gardner and Garrett (1988) discussed three internal subdivisions of the marketing discipline, the services/products dichotomy, the consumer goods/industrial goods dichotomy, and the domestic marketing/international marketing dichotomy. The debate with which this paper engages is therefore really only part of a wider debate about the proper delineation of boundaries within the field of marketing. The boundaries that are in use today reflect 'common sense' divisions that were made in the early days of the scientific study of marketing. In effect, we have been presented by our forbears with a clustering of marketing phenomena that is not grounded in formal systematics, and have chosen to live with it. We continue to assign 'marketing specimens' to these clusters without asking whether they are fundamentally appropriate or not. There are, of course, good reasons for doing this. Most prominently, an accepted clustering facilitates 
communication by creating a common language within the discipline. Because this language is also more or less common to academics and practitioners, it is arguably of even greater value, since at one level it may facilitate the transfer of knowledge (in both directions) between scholars and marketers. For an academic to advocate the development of a new and different clustering would, in all likelihood, necessitate the development of a new language which would initially be peculiar to the academic world, and might therefore promote the alienation of the practitioner from academic research.

On the other hand, we have seen that certain authorities regard scientifically based taxonomies as fundamental to 'good science'. Is this assertion only applicable to the natural sciences? Clearly this is a debate worth engaging with, even if the conclusion is that the analogy with the natural sciences is not appropriate (not 'physics envy' but perhaps 'zoology envy'). The question arises: to what extent should we heed the biological analogy? In the natural sciences, to ignore scientific evidence and insist on using ‘folk taxonomies' (Mezzich and Solomon 1980) would be unconscionable. But, of course, many people would argue that in the organisational sciences we are dealing with social phenomena, so that there is no underlying 'real' system of classification to be discovered - whereas in the natural world there are very real and (today) easily demonstrated differences in the genetic codes of mammals and reptiles, for example. However, McKelvey (1982) has argued at length that there are sufficient similarities between organisations and biological organisms to support the application of biological thinking to organisation studies, while McCarthy (1995) and McCarthy and Ridgway (2000) have done extensive conceptual and empirical work to apply the biological analogy to the classification of manufacturing systems. 
In conclusion let us return to Fern and Brown's argument that the industrial/consumer dichotomy is unjustifiable. While close to this point of view, the argument presented here is slightly different. The industrial/consumer marketing dichotomy is a 'folk taxonomy' and a 'special taxonomy'. In other words, it emerged from 'common sense' observation of the world rather than from formal taxonomic investigation, and it has limited validity and applicability. It is the task, perhaps even the duty, of the academic community to question knowledge that is 'takenfor-granted' in this way. The next logical step is to develop a formal marketing taxonomy that is grounded in empirical data.

For those people who like clarity, this paper ends with a clear answer to the question 'is there a difference between industrial and consumer marketing?' The answer is 'yes and no'. To use the language of philosophy, the distinction between industrial and consumer markets is contingent, but it is not necessary. 'Yes', in a narrow sense - when considered along a number of contingent dimensions, industrial and consumer markets are often classified differently (exactly what one would expect from a special classification system). In consequence, appropriate marketing strategies for industrial markets are often different from those for consumer markets. But, 'no', in any absolute sense; it is a contingent distinction, not a necessary distinction. Where the contingent circumstances of a consumer market are those found typically in a business market (for example, a small number of technically qualified buyers each of whom represents a substantial share of the market), then the strategies commonly employed in business markets are appropriate. 


\section{REFERENCES}

Anderson, J C and Narus, J A (1999). Business Market Management: Understanding, Creating, and Delivering Value. Englewood Cliffs NJ: Prentice Hall.

Barber, C (2008). Notes on Poverty and Inequality. Oxford: Oxfam, accessed at www.oxfam.org, $19^{\text {th }}$ January 2012.

Blackwelder, R E (1967). Taxonomy: A Text and Reference Book. New York: Wiley.

Carper, W B, and Snizek, W E (1980). The Nature and Types of Organizational Taxonomies: An Overview. Academy of Management Review, 5(1), 65-75.

Chamberlin, E H (1946). The Theory of Monopolistic Competition, $5^{\text {th }}$ edition. Cambridge, MA: Harvard University Press.

Chisnall, P M (1989). Strategic Industrial Marketing. Hemel Hempstead: Prentice Hall.

Chrisman, J J, Hofer, C W, and Boulton, W R (1988). Toward a System for Classifying Business Strategies. Academy of Management Review, 13(3), 413-428.

Cova, B and Salle, R (2008). Marketing solutions in accordance with the S-D logic: Co-creating value with customer network actors. Industrial Marketing Management, 37, 270-277.

Coviello, N E and Brodie, R J (2001). Contemporary Marketing Practices of Consumer and Business-to-Business Firms: How Different Are They? Journal of Business and Industrial Marketing, 16(5), 382-400.

Dwyer, F R and Tanner, J F (2002). Business Marketing: Connecting Strategy, Relationships, and Learning, $2^{\text {nd }}$ edition. Boston: McGraw Hill. 
Fern, E F and Brown, J R (1984). The Industrial/Consumer Marketing Dichotomy: A Case of Insufficient Justification. Journal of Marketing, 48 (Spring), 68-77.

Ford, D, Berthon, P, Brown, S, Gadde, L-E, Håkansson, H, Naudé, P, Ritter, T and Snehota, I (2002), The Business Marketing Course: Managing in Complex Networks, Chichester: Wiley

Ford, D, Gadde, L-E, Håkansson, H and Snehota, I (2011), Managing Business Relationships, $3^{\text {rd }}$ edition, Chichester: Wiley

Gross, A C, Banting, P M, Meredith, L N and Ford I D (1993). Business Marketing, Boston: Houghton Mifflin.

Lichtenthal, D, Iyer, G, Busch, P S and Tellefsen, T (2006). We are all business marketers now. Journal of Business and Industrial Marketing, 21/7, 414-421.

Lichtenthal, D and Mummalaneni, V (2009). Commentary: Relative Presence of Business-toBusiness Research in the Marketing Literature: Review and Future Directions. Journal of Business-to-Business Marketing, 16, 40-54.

Lilien, G L (1987). Business Marketing: Present and Future. Industrial Marketing and Purchasing, 2(3), 3-21.

Mattsson, L-G (1997). 'Relationship Marketing' and the 'Markets-as-Networks' Approach - a Comparative Analysis of Two Evolving Streams of Research. Journal of Marketing Management, 13(5), 447-461.

McCarthy, I (1995). Manufacturing Classification: Lessons from Organizational Systematics and Biological Taxonomy. Integrated Manufacturing Systems, 6(6), 37-48.

McCarthy, I and Ridgway, K (2000). Cladistics: a Taxonomy for Manufacturing Organizations. Integrated Manufacturing Systems, 11(1), 16-29. 
McKelvey, B (1982). Organizational Systematics: Taxonomy, Evolution, Classification. Berkeley: University of California Press.

Mezzich, J E, and Solomon, H (1980). Taxonomy and Behavioral Science. London: Academic Press.

Pels, J (1999). Exchange Relationships in Consumer Markets? European Journal of Marketing, $33(1 / 2), 19-37$.

Quicke, D L J (1993). Principles and Techniques of Contemporary Taxonomy. London: Blackie Academic \& Professional.

Sheth, J N, Gardner, D M and Garrett, D E (1988). Marketing Theory: Evolution and Evaluation. New York: Wiley.

Simkin, L (2000). Marketing is Marketing - Maybe! Marketing Intelligence and Planning, 18(3), $154-158$.

Webster, F E (1991). Industrial Marketing Strategy $3^{\text {rd }}$ edition. New York: Wiley.

Wilson, D (1999). Organizational Marketing. London: International Thompson.

Wilson, E and Woodside, A (2001). Executive and Consumer Decision Processes: Increasing Useful Sensemaking by Identifying Similarities and Departures. Journal of Business and Industrial Marketing, 16(5), 401-414. 


\section{GLOSSARY}

Cladism. A theory of classification which groups entities strictly according to lines of descent.

Classification. The actual construction of a classification scheme and the identification and assignment of entities to formally recognised classes.

Numerical taxonomy. Broadly any numerical approach to taxonomy (including cladistics) but now widely employed to refer to phenetic methods.

Operational taxonomic unit (OTU). The lowest ranking taxa employed in a particular study.

Phenetics. Clustering taxa on the basis of observable characteristics such as appearance and behaviour, rather than on the basis of evolutionary descent.

Phyletics, phylogenetics. The study of evolutionary lines of descent of entities from their ancestors for the purpose of discovering delimitable groupings and explaining their origin.

Systematics. The science given over to the study of the diversity of form.

Taxon (pl. taxa). A taxonomic group distinct enough to be formally recognized and named as a definite category.

Taxonomic character. A property or attribute that varies from one entity to another and has discriminatory power.

Taxonomy. The development of theories and methods for classifying things; the theory and practice of classification.

Source: based on McCarthy (1995), McKelvey (1982), Quicke (1993) 